\title{
Recent Publications
}

\section{BOOK REVIEWS}

Auerbach on Microfilm Readers/Printers. Philadelphia, Pa.: Auerbach Publishers, 1972. 128 p. $\$ 19.95$.

Rapid advances in computer and microform technology have encouraged a new class of publication-the technical report issued by commercial firms specializing in the analysis of technical information. This type of technical report sometimes appears as "near print" and is usually available only through a subscription service. Auerbach's Computer Technology Reports constitute a highly successful, respected series of documents upon which the title being reviewed is based. Occasionally a series of such reports, if properly rewritten and edited, forms the basis for a significant monograph in a special area. It seems to this reviewer that in this particular instance the publisher lost an opportunity to create an informative, readable monograph from revised technical reports. The result is an incoherent mishmash lacking in continuity and whose justification is extremely fragile.

According to the book jacket, Auerbach on Microfilm Readers/Printers is "an expansion of material from Auerbach's Computer Technology Reports, prepared and edited by the publisher's staff of EDP experts." The preface goes on to state that the book is intended for "all who use microfilm." Unfortunately, the lay reader who is expecting to find enlightenment on the subject of this book will be disappointed. For authoritative and accurate information, especially for library applications, he should turn to Library Technology Reports.

Nine chapters deal with image rotation, variable magnification, wall projection, portability, automated retrieval, and related subjects. Parts of each chapter are also devoted to the mechanical and optical operating principles of a variety of viewers intended for flat film and roll film. Most of the chapters are too brief to contain any critical information. The chapter on portable readers contains exactly two pages of text, that on external projectors only one and a half pages, and that on image rotators less than two pages. Despite the title of the book, only one chapter containing thirteen pages actually deals with reader/ printers. And this short chapter deals with only two of them, the discontinued DASA Mark 18 and the $3 \mathrm{M} 400$ series.

The book presupposes substantial technical knowledge (or interest) on the part of the reader. For example, pages $40-43$ deal with wiper switches, potentiometers, planoconvex and double-convex lenses, and the dove prism. The complexity of the technical writing is illustrated by the following extract on the operation of the dove prism:

Now consider an arrow pointing into the paper at right angles to the lower arrow and intersecting it at its midpoint. This arrow is shown on Figure 6-2 as a dot, which represents its intersection with the plane of the paper. The ray from its midpoint will coincide with the corresponding ray from the other arrow, the ray from the point of the arrow will run parallel to it below the plane of the paper, and the ray from the tail of the arrow will run parallel to it above the plane of the paper. Therefore, this arrow will appear unchanged in direction when viewed through the dove prism.

The considerations of the preceding paragraph demonstrate a significant property of dove prisms: Object lines perpendicular to the base surface of the prism will appear to be rotated 180 degrees by the prism, whereas object lines parallel to surface will not appear to be rotated. It follows that if a dove prism is rotated above an object, the object will appear to rotate; therefore, the dove prism in the Recordak Motormatic reader causes the image to rotate.

One would hope that technical terminology with which the book abounds would be explained in a glossary. Indeed there is a glossary, but many of the terms in the glossary do not even appear in the text, and those that are needed are often not in the glossary! It is surprising to this reviewer that arrangements were not made to use appropriate terms from the National Microfilm Association's Glossary of Micrographics, a 1971 industry standard based upon 
four earlier editions published over the course of a decade.

About one third of the book is made up of charts comparing selected features of ninety-two pieces of equipment. These charts are sometimes incomplete; for instance in eighteen cases the type of construction employed for the equipment is either not stated or is "not known."

The text erroneously states that Library Resources, Inc. is the manufacturer of a high magnification lap reader. Library Resources, Inc., does market such a viewer, but it is manufactured by Technicolor.

One wonders how valid can be the publisher's claim that "the material in this volume has been updated prior to publication and is as current as possible." Despite the fact that Library Resources, Inc. has mounted a very substantial and heavily publicized development and marketing program for its Microbook $₫$ ultrafiche (Encyclopedia Britannica's Library of Civilization), nowhere in the book is this contribution to ultrafiche technology even mentioned. The editors lead the readers to believe that NCR's PCMI system is virtually the sole representative of the ultrafiche technique.

Auerbach on Microfilm Readers/Printers contains numerous schematic and photographic illustrations, but, relative to equipment, is almost completely lacking in evaluative comments on ease of use, durability of construction or simplicity of servicing. As for user requirements, little is said about the suitability of equipment for a given application.

There is no bibliography and no mention of the NMA's Guide to Microreproduction Equipment. A weak conclusion summarizes the usual "advantages" of microform-compactness, lightness, and cheapness-without renewing and reemphasizing microform's stated dependence upon adequate indexing or bibliographic control systems.

As for $35 \mathrm{~mm}$ roll microforms likely to be found in libraries, no viewers suitable for this type of material are described in significant detail. Conspicuously absent is the discontinued-but widely installed-Recordak MPE. Information Design's library viewer, the Model 16/35, appears only in the comparative charts.
Auerbach could have performed a real service for readers (human, that is) by putting together a chapter summarizing the human and design problems associated with building microform viewers. At least in this way, the lay reader could have come to appreciate the optical and mechanical limitations which have thus far prevented the design, construction and marketing of greatly improved viewers. Auerbach on Microform Readers/Printers may be readable and understandable by the microform systems engineers, the systems analyst, or the manager of a data processing installation. The book may be suitable for technical libraries of micrographic equipment manufacturers, but its general utility is doubtful. Not recommended for the college or university library.-Allen B. Veaner, Assistant Director for Bibliographic Operations, Stanford University Libraries.

\section{Stueart, Robert D. The Area Specialist Bib- liographer: An Inquiry into His Role.} Metuchen, N.J.: Scarecrow Press, 1972. $152 \mathrm{p}$.

The development of the area specialist bibliographer since World War II represents a major new direction for academic librarianship in this country, and in this study Mr. Stueart attempts to learn something about this phenomenon. Bibliographers, their backgrounds and their roles, are examined, as they are perceived by themselves and by others.

The study is based largely on responses to 362 questionnaires which were sent to area specialist bibliographers, library administrators, and faculty members who are teaching in area study programs in ARL institutions. The questions relate to the bibliographers' preparation for their assignments and the respondents' notions of precisely what their functions should include.

In the matter of preparation, nothing significant is learned, except that the backgrounds and training of the bibliographers who responded vary greatly, and they seem to bear no relationship whatever to what faculty and library administrators feel is necessary in the way of background.

Respondents were given a list of tasks which were assumed to be associated with bibliographers' responsibilities and were 